\title{
Sequence Structure and Thermotropic Liquid Crystalline Properties of Aromatic-Aliphatic Polyesteramides Based on Dimethylbenzidine, Hexamethylene Glycol and $p$-Terephthalyl Chloride ${ }^{\dagger}$
}

\author{
Biao DaI, Xiaogong WANG, Yanfang GaO, Qixiang ZHoU, \\ and Deshan $\mathrm{LIU}^{\dagger \dagger}$ \\ Department of Chemical Engineering, Institute of Polymer Science and Engineering, \\ Tsinghua University, Beijing 100084, People's Republic of China
}

(Received July 3, 1997)

\begin{abstract}
Thermotropic aromatic-aliphatic liquid crystalline polyesteramides (PEAs) with different sequence structures were synthesized from dimethylbenzidine (DMBD), hexamethylene glycol (HG), and p-terephthalyl chloride (TPC) by different feeding order of monomers. Structure parameters, number average length $\left(L_{n}\right)$ and random degree $(B)$, were obtained by NMR and a computer program. The relation of sequence structure and liquid crystalline phase transition behavior of PEAs obtained was studied.

KEY WORDS Polyesteramide / Liquid Crystal / Sequence Structure /
\end{abstract}

Polyesteramides synthesized from three monomers, p-terephthalylchloride (TPC), dimethylbenzidine (DMBD), and hexamethylene glycol (HG), were thermotropic liquid crystalline polymers and their liquid crystalline behavior was reported. ${ }^{1}$ The polyesteramides obtained were random or block polymers because of the different reactivity of $-\mathrm{OH}$ and $-\mathrm{NH}_{2}$ with $-\mathrm{COCl}$. The effect of distribution of two chain segments, polyester chain segment and polyamide chain segment, which exhibited different rigidity on properties of polymers, specially on liquid crystalline phase transition, was obvious. ${ }^{2,3}$

In this paper polyesteramides with different sequence distributions were synthesized by changing the feeding order of monomers and the relationship between liquid crystalline properties and sequence structure was studied.

\section{EXPERIMENTAL}

The monomers, TPC, DMBD, and HG, were used for obtaining the polyesteramides (PEAs) by low temperature solution polycondensation. ${ }^{4}$ Number average sequence length $\left(L_{n}\right)$ and random degree $(B)$, which characterized the sequence distribution of polyesteramide chain segments, were obtained by ${ }^{1} \mathrm{H}$ NMR spectra and a computer program for the resolution of NMR spectra with overlapping peaks. ${ }^{5,6}$ The Unity-200 NMR spectrometer was used for recording NMR spectra of polyesteramides and the solution used was approximately $2-3 \%(\mathrm{w} / \mathrm{w})$ in $\mathrm{NMP} / \mathrm{LiCl}(3 \% \mathrm{w} / \mathrm{v})$. The liquid crystalline phase behavior was determined by Du-Pont $1090 \mathrm{DSC}$ under $\mathrm{N}_{2}$ at heating rate of $10^{\circ} \mathrm{C} \mathrm{min}^{-1}$. The inherent viscosity $\left(\eta_{\text {inh }}\right)$ measurement was found with a Ubbelhode type viscosimeter at $0.5 \mathrm{~g} \mathrm{dL}^{-1}$ polyesteramide concentration at $30^{\circ} \mathrm{C}$.

\section{RESULTS AND DISCUSSION}

Synthesis of PEAs with Different Sequence Structures Using different feeding orders, as shown in Table I, PEAs which exhibited different sequence structures but were based on same mole ratio of $-\mathrm{OH}$ group and $-\mathrm{NH}_{2}$ were synthesized. The Table II listed $\eta_{\text {inh }}, B$, and $L_{n}$ of PEAs produced and NMR data, in which the $P_{\mathrm{dtd}}, P_{\mathrm{dth}}$, $P_{\mathrm{hth}}, P_{\mathrm{dt}}$, and $P_{\mathrm{ht}}$ represent the mol ratio of DTD, DTH, HTH, DT, and HT chain structure units and the $P_{\mathrm{dh}}$ and $P_{\mathrm{hd}}$ represent the possibility of $\mathrm{H}$ and $\mathrm{D}$ monomer

Table I. The feeding methods of monomers

\begin{tabular}{cl}
\hline Code & \multicolumn{1}{c}{ Feeding methods } \\
\hline I & $(\mathrm{HG}+\mathrm{DMBD}) \rightarrow \mathrm{AA}^{\mathrm{a}} \rightarrow \mathrm{TPC}$ \\
II & $\mathrm{HG} \rightarrow \mathrm{AA} \rightarrow \mathrm{TPC} \rightarrow \mathrm{DMBD}$ \\
III & $\mathrm{HG} \rightarrow \mathrm{AA} \rightarrow \mathrm{TPC}_{1}{ }^{\mathrm{b}} \rightarrow \mathrm{DMBD} \rightarrow \mathrm{TPC}_{2}{ }^{\mathrm{b}}$ \\
IV & $\mathrm{DMBD} \rightarrow \mathrm{AA} \rightarrow \mathrm{TPC}_{1} \rightarrow \mathrm{HG} \rightarrow \mathrm{TPC}_{2}$ \\
\hline
\end{tabular}

${ }^{\mathrm{a}}$ Acid accepter. ${ }^{\mathrm{b}} \mathrm{TPC}_{1} / \mathrm{TPC}_{2}=1$ (mol).

Table II. NMR data and sequence parameters of PEAs by different feeding methods

\begin{tabular}{lllll}
\hline Feeding methods & \multicolumn{1}{c}{ I } & \multicolumn{1}{c}{ II } & III & IV \\
\hline$\eta_{\text {inh }}\left(\mathrm{dL} \mathrm{g}^{-1}\right)$ & 0.62 & 0.51 & 0.63 & 0.70 \\
$P_{\mathrm{dtd}}$ & 0.3735 & 0.3696 & 0.3676 & 0.3783 \\
$P_{\mathrm{dth}}$ & 0.2434 & 0.2625 & 0.2532 & 0.2439 \\
$P_{\mathrm{hth}}$ & 0.3831 & 0.3678 & 0.3792 & 0.3778 \\
$P_{\mathrm{dt}}$ & 0.4952 & 0.5009 & 0.4942 & 0.5003 \\
$P_{\mathrm{ht}}$ & 0.5048 & 0.4991 & 0.5058 & 0.4997 \\
$P_{\mathrm{dh}}$ & 0.2458 & 0.2620 & 0.2562 & 0.2438 \\
$P_{\mathrm{hd}}$ & 0.2411 & 0.2629 & 0.2503 & 0.2441 \\
$L_{n \mathrm{a}}{ }^{\mathrm{a}}$ & 4.07 & 3.82 & 3.90 & 4.10 \\
$L_{n \mathrm{~b}}$ & 4.15 & 3.80 & 4.00 & 4.10 \\
$B$ & 0.49 & 0.53 & 0.51 & 0.49 \\
\hline
\end{tabular}

${ }^{a}$ Sequence length of polyamide segment. ${ }^{\mathrm{b}}$ Sequence length of polyester segment.

\footnotetext{
+ Supported by the Special Foundation of State Education Committee of China for Doctoral Program

${ }^{\dagger}$ To whom correspondence should be addressed.
} 


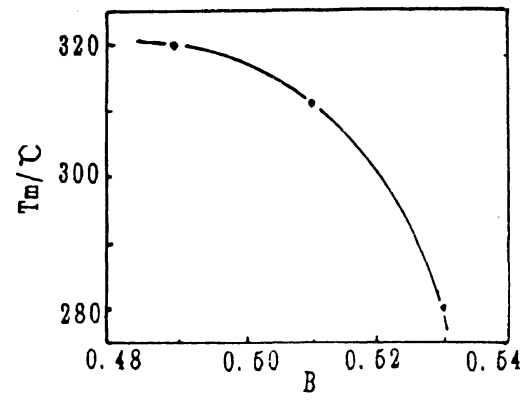

Figure 1. The relation of $T_{\mathrm{m}}$ and $B$.

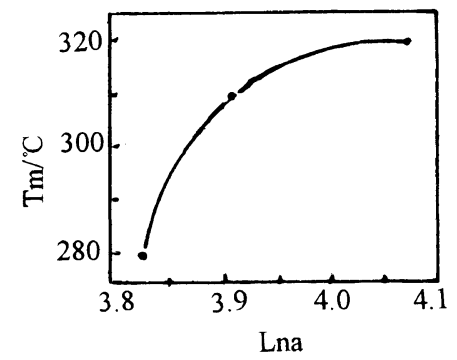

Figure 2. The relation of $T_{\mathrm{m}}$ and $L_{n \mathrm{a}}$

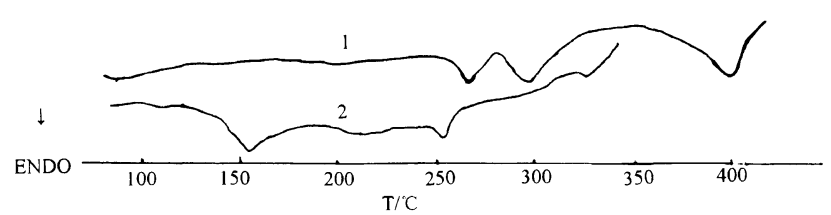

Figure 3. The DSC curves of PEAs. 1, DMBD $/ \mathrm{HG}=50 / 50(\mathrm{~mol})$; 2, $\mathrm{DMBD} / \mathrm{HG}=20 / 80(\mathrm{~mol})$.

units after $\mathrm{D}$ and $\mathrm{H}$ monomer units in the polymer chain, respectively.

Table II shows that $B$ of PEAs produced by method I and method IV in which the DMBD was added into the reaction system at first step were less than that of PEAs obtained by methods II and III in which the HG was fed into reaction system at first step. This proves that the methods in which the monomer with less reactivity hydroxy group, $\mathrm{HG}$, was fed at first step reaction into polycondensation system are favorable for obtaining PEAs with bigger $B$ and smaller $L_{n} \cdot{ }^{7}$

The difference between the $B$ of aromatic PEAs produced from TPC, DMBD, and bisphenol A (BPA) by I and IV and that of PEAs produced by II and III in last study ${ }^{8}$ is bigger than the difference between the $B$ of aromatic-aliphatic PEAs obtained by I and IV and that of PEAs obtained by II and III in this study. The reason is that the reactivity of aliphatic hydroxy group with TPC is bigger than that of aromatic hydroxy group with TPC. Thus the difference of reactivity with TPC between the amine group of DMBD and the hydroxy group of BPA is also bigger than that of reactivity with TPC between the amine group of DMBD and the hydroxy group of $\mathrm{HG}$ in the unequilibrium polycondensation system.

\section{Effects of Sequence Structures of PEAs on Melting} Temperature $\left(T_{\mathrm{m}}\right)$

Because of differences of rigidity between polyamide
Table III. Phase transition temperture of PEAs

\begin{tabular}{cccccccc}
\hline $\mathrm{DMBD} / \mathrm{HG} / \mathrm{mol}$ & $T_{\mathrm{m}} /{ }^{\circ} \mathrm{C}^{\mathrm{a}} T_{\mathrm{i}} /{ }^{\circ} \mathrm{C}^{\mathrm{a}}$ & $T_{\mathrm{d}} /{ }^{\circ} \mathrm{C}^{\mathrm{a}}$ & $L_{n \mathrm{a}}$ & $L_{n \mathrm{e}}$ & $B$ & $L_{n \mathrm{a}} / L_{n \mathrm{e}}$ \\
\hline $20 / 80$ & 154 & 256 & 327 & 3.92 & 16.26 & 0.32 & 0.24 \\
$40 / 60$ & 253 & 276 & - & 3.47 & 5.00 & 0.49 & 0.69 \\
$50 / 50$ & 268 & 298 & 400 & 3.82 & 3.80 & 0.53 & 1.01 \\
$60 / 40$ & 313 & No & - & 5.04 & 3.32 & 0.52 & 1.52
\end{tabular}

${ }^{\mathrm{a}}$ By DSC.

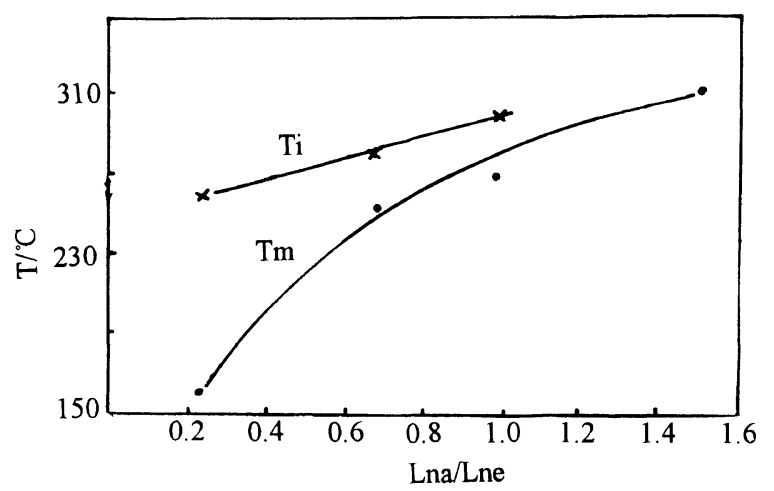

Figure 4. $T_{\mathrm{m}}$ and $T_{\mathrm{i}}$ of PEAs vary with $L_{n \mathrm{a}} / L_{n \mathrm{e}}$.

and polyester segments $T_{\mathrm{m}}$ was more strongly affected by the $L_{n \mathrm{a}}$ or $B$ of PEAs synthesized by method II and $-\mathrm{OH} /-\mathrm{NH}_{2}=1(\mathrm{~mol})$. Figures 1 and 2 show that a little change of $L_{n \mathrm{a}}$ or $B$ could make the $T_{\mathrm{m}}$ of PEAs change a lot.

\section{On Chain Composition of PEAs}

PEAs with different chain composition were synthesized by changing molar ratio of $\mathrm{DMBD} / \mathrm{HG}$ and method II. The $L_{n a} / L_{n \mathrm{e}}$ should approximately be equal to $\mathrm{DMBD} / \mathrm{HG}(\mathrm{mol})$ if the accuracy of analysis method of $L_{n}$ is enough.

As indicated by DSC curves (Figure 3) and data in Table III the liquid crystalline phase transition temperature $\left(T_{\mathrm{i}}\right)$ of PEAs could be observed.

As shown in Figure 4 with increasing rigid polyamide chain segment length, $T_{\mathrm{m}}$ and $T_{\mathrm{i}}$ of PEAs produced increased but the change of $T_{\mathrm{m}}$ was much greater.

\section{REFERENCES}

1. B. Dai, H. Wang, Q. Zhou, and D. Liu, National Symposium on Polymers, Preprints, pp 587-588, Dec. 1995, Guangzhou, P.R. China.

2. D. Liu, H. Wang, M. Chen, and Q. Zhou, Polym. Mater. Sci. Eng., 13, 57 (1997).

3. L. Gu, D. Liu, X. Wang, C. Yang, and Q. Zhou, ACTA Polymerica Sinica, 1, 65 (1994).

4. P. W. Morgen, "Polycondensation Polymer by Interfacial and Solution Reactions," Wiley-Interscience, New York, N.Y., 1965.

5. L. Gu, X. Wang, D. Liu, and Q. Zhou, J. Tsinghua University, 32, 75 (1992).

6. R. Yamadera and M. Murano, J. Polym. Sci., Part A-1, 5, 2259 (1967).

7. X. Lu, L. Gu, X. Wang, Y. Xu, Q. Zhou, and D. Liu, Polym. Mater. Sci. Eng., 11, 14 (1995).

8. B. Dai, Y. Gao, X. Wang, Q. Zhou, and D. Liu, Chinese J. Polym. Sci., 15 (1997), in press. 